\title{
Analyzing the Financial Implications in Iran Bank's Strategic Plan Using the Balanced Score Card
}

\author{
Hadi Ghadimi ${ }^{1}$, Sina Nematizadeh ${ }^{2}$ \\ ${ }^{1}$ M.A of Commercial Management, Tehran Azad University, Central Tehran Branch, Tehran, Iran \\ ${ }^{2}$ Department of Business Management, Faculty of Islamic Azad University, Central Tehran Branch, Tehran, Iran \\ Email: Ghadimi789@gmail.com, Nematizadeh51@yahoo.com
}

Received 17 February 2016; accepted 24 April 2016; published 27 April 2016

Copyright (C) 2016 by authors and Scientific Research Publishing Inc.

This work is licensed under the Creative Commons Attribution International License (CC BY). http://creativecommons.org/licenses/by/4.0/

c) (i) Open Access

\begin{abstract}
Studying the process of annual balance sheets, interests and losses of Iran Zamin Bank in relation to other banks has a low share. Thus, the rise of guidelines in editing framework of strategic plan is necessary in this bank. The study analyzes the strategic plan of Iran Zamin Bank. It also analyzes the financial implications in balanced score card through the relationship among profitability, productivity and financial growth. We introduced two indexes for productivity. The results are as follows. There's not any negative and significant relationship between the capitation of profit index and capitation index in terms of administrative costs comparing all costs. There's a positive and significant relationship between the financial implication indexes and profitability index. There's a significant and negative relationship between productivity indexes and financial growth index. Therefore, the effect of strategic plan can be evaluated by using the available tools and the organization's performance can be assessed.
\end{abstract}

\section{Keywords}

Finance, Iran Bank, Balanced Score Card

\section{Introduction}

In today's complicated business, the traditional plan based on budget or prediction can't be accountable to the present challenges. Organizations should analyze their internal and external situations and then present a suitable strategy. The strategic plan describes the organization's strategy and it helps people understanding future's organization by displaying the causal relationship between strategies and goals. 
Planning is the starting point of all movements in traditional perspective. The importance of this perspective is revealed to all and it's one of the most fundamental tasks of management. In line with this perspective, the human society proceeded from simple to complicated, acceleration and huge evolution in economic, social, cultural, political and technological factors created new perspectives. According to this plan in management, new theories and approaches were introduced in relation to different needs and many theorists paid attention to it. In a way, many perspectives and methods can be distinguished. Therefore, in this paper some explanations are presented in order to become familiar with researcher's results in management and plan. It also explains different strategic categories in management and reviews the first methods in strategic management. It should be noted that the suggested issues are turning points which were shaped in strategic management evolution. We introduced the most important ones.

On the other hand, the progression of subjects does not mean outdating other method but it shows evolutionary aspects which can be used in mixed methods.

\section{Statement of the Problem}

The strategic plan has been one of the most concerns of managers and beneficiaries of organization. Strategic plan and performance assessment can lead to performance improvement of each organization especially service units. Consequently, the motive and opportunity for quality increase of service and product performance are created.

The complexities of business competition arena and increase of customer's expectations have revealed the strength and weakness points of organization and improvement of productivity. Therefore, one of the most important concerns of today's organization is achieving a performance evolution method that is comprehensive, flexible and reliable. Organizations can gain enough information about their circumstances and learn from their errors. The short way of achieving the organization's goals is that the suggested method be in line with the organization's strategy because the strategic plan of control plans and performance process are guarantees of the fundamental goals and each organization perspective. To do that the need of using an evaluative measurement system which is based on strategy is felt for controlling all organization's parts for each moment and it's necessary for comparing them with all plans and goals (Mohebi Moghadam, 2008: p. 2).

Strategy for responding to external situation and for adapting bank with them is expanded during the time. For example absorbing the cheap cost of resources was introduced after imposition factor out of bank as "decrease od interest rate in bank system" in mobilizing bank resource.

This subject is analyzed in this paper: "How much strategic plan of Iran Zamin Bank affects the numbers of balanced sheet, profit and harms of this bank?”

\section{Population of the Research}

Iran Zamin Bank

A: place scope: central departments of Iran Zamin Bank,

B: time scope: 2011 to 2013,

C: subject: financial strategic management.

\section{Review of the Related Literature}

Piter Draker challenged management basics in 1950. He believed that the strategy should be in pivot for organization analyses and called it goal oriented management. Goal oriented management led to creating engineering methods, business processes and performance management such as making pattern, comprehensive quality management, costs based on goal and finally BSC model for productivity. In fact, the main elements of BSC model are management of information based on the goal. Moreover, the suggested model focused on feedback results more than ever. Piter Draker recognizes the organization's resource as the only human resource. He believed that each firm has two important tasks: Marketing (focusing on consumer) and creativity (focusing on product). However, Draker believed that there's a limited knowledge in the domain of productivity and measurement method.

Imad Alsyouf (2006) represented a strategic system for measuring performance and maintenance. He used the BSC framework to evaluate the maintenance share in line with strategic goal. 
Wong-On-Wing et al. [1] concluded that the financial performance indexes have harmful consequences and it can lead to occupational conflicts and distrust of supervisors. A mere focus on traditional financial accounting such as return rate of assets was criticized [2].

The operational goals are concise statements explain the activities necessary for a successful strategy implementation. Niven [3], Goran Olve and Sjostrand [4] found that the operational measurements are instruments used for assuring the realization of goals and moving in line with the strategy successful implementation. The results received from Arian and Boglino [5] in line with the studies of Goran Olve and Sjostrand [4] show that these measurements can identify the weakness and strength points of organization and provides a suitable improvement opportunity.

Hoque and James [6] conducted a study in Australia firms. They also studied conventional criteria of balanced evaluation in these firms. The goal of this study is analyzing the relationship of balanced assessment use with organization size, product life cycle, market authority and organization performance. The results showed that there's a positive relationship between the conventional criteria of balanced evaluation and better performance. Although based on their research, non-financial performance has a more role in company's improvement.

The goal of a study conducted by Daneshfard, Vahdani and Aghaz (2010) with the title of "analyzing the role of BSC in improvement of organization's performance" was that the relationship of balanced evaluation could improve indexes of customer pivot in order to improve the products properties and to increase the value for customers. The company could build a good relationship through meetings with customers and creating win to win with customers. It can also identify the needs of customers and plan to resolve it. Based on defining the index of "orientation to massive national contracts", Sairan became a reliable brand in these years.

\section{Hypotheses}

1) There's a positive and significant relationship between indexes of productivity and profitability.

2) There's a positive and significant relationship between profitability and financial growth.

3) There's a positive and significant relationship between productivity and financial growth.

\section{Results}

In order to test the hypotheses, first we introduce the productivity, profitability and financial growth. For productivity the capitation of administrative costs were used in relation to all costs; for profitability rate, the capitation of profitability index before deduction of tax and for financial growth, the capitation of deposit was used for Iran Zamin Bank.

The estimated equation can be shown for analyzing the hypotheses:

The equation of the relationship between the productivity and profitability indexes

$$
\begin{aligned}
& \text { profit }_{i j}=\alpha+\beta_{1} \operatorname{cost}_{i j}+\varepsilon_{i j} \\
& \text { profit }_{i j}=\alpha+\beta_{1} R O A_{i j}+\varepsilon_{i j} .
\end{aligned}
$$

The equation of the relationship between the financial growth and profitability indexes

$$
\text { deposit }_{i j}=\alpha+\beta_{1} \text { profit }_{i j}+\varepsilon_{i j} \text {. }
$$

The equation of the relationship between the financial growth and productivity indexes

$$
\begin{aligned}
& \text { deposit }_{i j}=\alpha+\beta_{1} \operatorname{cost}_{i j}+\varepsilon_{i j} \\
& \text { deposit }_{i j}=\alpha+\beta_{1} R A_{i j}+\varepsilon_{i j} .
\end{aligned}
$$

profit $_{i j}$ : The capitation of impure profit after deduction of tax in province $i$ and year $j$.

$\operatorname{cost}_{i j}$ : The ratio of administrative cost capitation to all costs in province $i$ and year $j$.

$R O A_{i j}$ : The rate of tax input in province $i$ and year $j$.

deposit $_{i j}$ : The ratio of deposit capitation in province $i$ and year $j$.

\section{Estimation of Model}

\subsection{The Group Significance Test (Limer Test)}

1) The Limer test for equation of the relationship between the productivity and profitability 


$$
\begin{aligned}
& \text { profit }_{i j}=\alpha+\beta_{1} \operatorname{cost}_{i j}+\varepsilon_{i j} \\
& \text { profit }_{i j}=\alpha+\beta_{1} R O A_{i j}+\varepsilon_{i j} .
\end{aligned}
$$

\begin{tabular}{cccc}
\hline \multicolumn{4}{c}{ Redundant fixed effects tests } \\
\hline \multicolumn{4}{c|}{ Equation: EQ05 } \\
\hline \multicolumn{2}{c|}{ Test cross-section fixed effects } \\
\hline Prob. & d.f. & Statistic & Effects test \\
\hline 0.848 & $(31.63)$ & 0.712636 & Cross-section F \\
\hline
\end{tabular}

The $\mathrm{f}$ statistic in Limer test has the significance level of $84 \%$. It's more than the $10 \%$ significance level. Therefore, the result of Limer test for equation of productivity and profitability show that the summed data model has a more efficient than a data panel model. Therefore, the estimation of equation model between productivity and profitability will be a summed model.

2) The Limer test for the relationship between the financial growth and profitability indexes

$$
\text { deposit }_{i j}=\alpha+\beta_{1} \text { profit }_{i j}+\varepsilon_{i j}
$$

\begin{tabular}{cccc}
\hline & \multicolumn{3}{c}{$\begin{array}{c}\text { Redundant fixed effects tests } \\
\text { Equation: EQ02 } \\
\text { Test cross-section fixed effects }\end{array}$} \\
\hline Prob. & d.f. & Statistic & Effects test \\
\hline 0.0672 & $(31.63)$ & 1.562557 & Cross-section F \\
\hline
\end{tabular}

Because the $\mathrm{f}$ statistic of Limer test has a $6 \%$ significance level which is less than $10 \%$, it can be said that the equation estimation of the relationship between financial growth and profitability is more efficient than data panel.

3) The Limer test for the relationship between the financial growth and productivity indexes

$$
\begin{aligned}
& \text { deposit }_{i j}=\alpha+\beta_{1} \operatorname{cost}_{i j}+\varepsilon_{i j} \\
& \text { deposit }_{i j}=\alpha+\beta_{1} R O A_{i j}+\varepsilon_{i j}
\end{aligned}
$$

\begin{tabular}{cccc}
\hline \multicolumn{3}{c}{$\begin{array}{c}\text { Redundant fixed effects tests } \\
\text { Equation: EQ01 }\end{array}$} \\
& \multicolumn{2}{c}{ Test cross-section fixed effects } \\
\hline Prob. & d.f. & Statistic & Effects test \\
\hline 0.0762 & $(31.63)$ & 1.532014 & Cross-section F \\
0.0065 & 31 & 53.933985 & Cross-section chi-square \\
\hline
\end{tabular}

\begin{tabular}{cccc}
\hline \multicolumn{4}{c}{$\begin{array}{c}\text { Redundant fixed effects tests } \\
\text { Equation: EQ03 }\end{array}$} \\
Trob. & \multicolumn{2}{c}{ Test cross-section fixed effects } & Effects test \\
\hline 0.0626 & d.f. & Statistic & Cross-section F \\
0.0047 & $(31.63)$ & 1.579641 & Cross-section chi-square \\
\hline
\end{tabular}

Because the f statistic of Limer test has a $6 \%$ and $7 \%$ significance level which is less than $10 \%$, it can be said that the equation estimation of the relationship between financial growth and productivity is more efficient than data panel. 
Now, after determining the equation estimation and deciding how to estimate (using data panel or summed data) we estimate them.

\subsection{Equation Estimation}

1) First hypothesis (analyzing the relationship between productivity and profitability)

As it was showed before, the equation estimation for the first hypothesis would be like a summed data. The results are as follows:

$$
\begin{aligned}
& \text { profit }_{i j}=\alpha+\beta_{1} \operatorname{cost}_{i j}+\varepsilon_{i j} \\
& \text { profit }_{i j}=\alpha+\beta_{1} R O A_{i j}+\varepsilon_{i j} .
\end{aligned}
$$

\begin{tabular}{|c|c|c|c|c|}
\hline \multicolumn{5}{|c|}{ Dependent variable PROFIT } \\
\hline Prob. & t-statistic & Std. error & Coefficient & Variable \\
\hline 0.0027 & -3.126207 & $1.30 \mathrm{E}+11$ & $-4.06 E+11$ & COST \\
\hline 0.0000 & 36.85600 & $18,844,470$ & $6.95 E+08$ & C \\
\hline $2.03 E+09$ & \multicolumn{2}{|c|}{ Mean dependent variable } & 0.247024 & R-squared \\
\hline $5.92 E+09$ & \multicolumn{2}{|c|}{ S.D. dependent variable } & -40.135439 & Adjusted R-squared \\
\hline $2.51 E+21$ & \multicolumn{2}{|c|}{ Sum squared residual } & $6.31 \mathrm{E}+09$ & S.E. of regression \\
\hline 2.473836 & \multicolumn{2}{|c|}{ Durbin-Watson statement } & 0.645877 & F-statistic \\
\hline \multicolumn{4}{|c|}{0.910727} & Prob (F-statistic) \\
\hline Prob. & t-Statistic & Std. Error & Coefficient & Variable $j$ \\
\hline 0.6028 & 0.522111 & $146,921.2$ & $76,709.24$ & ROA \\
\hline 0.3548 & 0.929986 & $1.80 \mathrm{E}+08$ & $1.68 \mathrm{E}+08$ & $\mathbf{C}$ \\
\hline $1.25 \mathrm{E}+09$ & \multicolumn{2}{|c|}{ Mean dependent variable } & 0.000572 & R-squared \\
\hline $4.58 \mathrm{E}+09$ & \multicolumn{2}{|c|}{ S.D. dependent variable } & -0.010060 & Adjusted R-squared \\
\hline $2.00 \mathrm{E}+21$ & \multicolumn{2}{|c|}{ Sum squared residual } & $4.61 \mathrm{E}+09$ & S.E. of regression \\
\hline 1.906279 & \multicolumn{2}{|c|}{ Durbin-Watson statement } & 0.053774 & F-statistic \\
\hline \multicolumn{4}{|c|}{0.817125} & Prob (F-statistic) \\
\hline
\end{tabular}

Since, two indexes were introduced for productivity, above equations were used for analyzing this hypothesis.

The result of estimation showed that there's a negative and significant relationship between profit captivation index and captivation index compared to administrative costs to all costs (i.e. there's a positive and significant relationship between profitability and productivity because by decreasing the administrative costs to all costs the productivity will increase) but there's not any significant relationship between profit captivation and asset input rate.

2) Second hypothesis (analyzing the relationship between financial growth and profitability)

As it was discussed earlier, estimating the relationship between financial growth and profitability will be like data panel. Now after confirming the estimation, we need to analyze the data by Hasmen test to know whether the data panel is like constant effect or random effect. The results of Hasmen test are as follows.

\subsection{Selecting Constant or Random Effect}

The result of Hasmen test realizes the relationship between the capitation deposit and impure profit.

Correlated random effects-Hausman test Equation: EQ02

Test cross-section fixed effects

$\begin{array}{cccc}\text { Prob. } & \text { Chi-Sq. d.f. } & \text { Test summary } \\ \text { Chi-sq. statistic }\end{array}$


The Hasmen statistic includes degree of freedom K (the variable number of model). The K statistics is double of the degree of freedom (1) and the probability level of this statistic shows that the null hypothesis is not rejected for random effects. Thus, the estimation of data panel would be with random effects:

\begin{tabular}{ccccc}
\hline & \multicolumn{3}{c}{ Dependent variable: DEPOSIT } \\
\hline Prob. & t-Statistic & Std. error & Coefficient & Variable \\
\hline $\mathbf{0 . 0 0 0 7}$ & $\mathbf{3 . 5 0 7 5 5 3}$ & $\mathbf{5 . 7 0 E - 0 8}$ & $\mathbf{2 . 0 0 E - 0 7}$ & $\mathbf{P R O F I T}$ \\
$\mathbf{0 . 0 9 7 5}$ & $\mathbf{1 . 6 7 3 8 7 3}$ & $\mathbf{3 3 1 7 . 0 5 7}$ & $\mathbf{5 5 5 2 . 3 3 2}$ & $\mathbf{C}$ \\
4471.728 & Mean dependent variable & 0.015269 & R-squared \\
9012.684 & S.D. dependent variable & 0.004793 & Adjusted R-squared \\
$7.60 \mathrm{E}+09$ & Sum squared residual & 8991.059 & S.E. of regression \\
1.072163 & Durbin-Watson statement & 1.457525 & F-statistic \\
\hline
\end{tabular}

The result of estimation shows that there's a positive and significant relationship between financial growth (deposit capitation) and profitability (impure profit capitation before deduction of tax).

\subsection{Third Hypothesis (Analyzing the Relationship between Financial Growth and Productivity)}

As we discussed in Limer test, analyzing the relationship between the financial growth and productivity is more efficient in data panel. Therefore, we should find out whether the data panel has constant or random effect by Hasmen test. The results of Hasmen test is shown in the following table:

Result of Hasmen test for the relationship between deposit capitation and capitation of administrative cost to overall costs:

\begin{tabular}{|c|c|c|c|}
\hline \multicolumn{4}{|c|}{$\begin{array}{l}\text { Correlated random effects_-Hausman test } \\
\text { Equation: EQ01 } \\
\text { Test cross-section fixed effects }\end{array}$} \\
\hline Prob. & $\begin{array}{l}\text { Chi-sq. Statistic } \\
\text { Chi-Sq. d.f }\end{array}$ & & \\
\hline 0.6318 & 1 & 0.229663 & Cross-section random \\
\hline
\end{tabular}

The result of Hasmen test for the relationship between deposit capitation and input tax capitation

\begin{tabular}{ccrc}
\hline \multicolumn{4}{c}{$\begin{array}{c}\text { Correlated random effects-Hausman test } \\
\text { Equation: EQ01 }\end{array}$} \\
Test cross-section fixed effects & \\
\hline Prob. & Chi-sq. d.f. & Chi-sq. statistic & Test summary \\
\hline 0.9012 & 1 & 0.015410 & Cross-section random \\
\hline
\end{tabular}

The Hasmen statistic includes the degree of freedom K (the number of explanatory variable model). The $\mathrm{K}$ statistic is double of degree of freedom (1) and the probability level of this statistic for deposit capitation and administrative costs are $63 \%$ compared to all costs. They are $90 \%$ for the equation of deposit capitation. Since this rate is more than $5 \%$ level, the estimation with random effects in more efficient for these equations. The result of estimation is shown in the following table: 


\begin{tabular}{|c|c|c|c|c|}
\hline \multicolumn{5}{|c|}{ Dependent variable DEPOSIT } \\
\hline Prob. & t-statistic & Std. error & Coefficient & Variable \\
\hline 0.0757 & 1.796267 & 3351.423 & 6020.052 & $\mathrm{C}$ \\
\hline 0.0540 & -1.951654 & $1,203,643$ & $-2,349,096$ & COST \\
\hline 4529.341 & \multicolumn{2}{|c|}{ Mean dependent variable } & 0.014791 & R-squared \\
\hline 9050.165 & \multicolumn{2}{|c|}{ S.D. dependent variable } & 0.004310 & Adjusted R-squared \\
\hline $7.67 \mathrm{E}+09$ & \multicolumn{2}{|c|}{ Sum squared residual } & 9030.642 & S.E. of regression \\
\hline 1.041981 & \multicolumn{2}{|c|}{ Durbin-Watson statement } & 1.411206 & F-statistic \\
\hline \multicolumn{4}{|c|}{0.237849} & Prob (F-statistic) \\
\hline 0.0000 & 4.693914 & 1176.102 & 5520.524 & C \\
\hline \multirow[t]{2}{*}{0.0000} & -12.85371 & 0.854207 & -10.97973 & ROA \\
\hline & & & \multicolumn{2}{|c|}{ R-squared 0.022573} \\
\hline 8996.307 & \multicolumn{2}{|c|}{ S.D. dependent variable } & 0.012175 & Adjusted R-squared \\
\hline $7.52 \mathrm{E}+09$ & \multicolumn{2}{|c|}{ Sum squared residual } & 8941.374 & S.E. of regression \\
\hline 1.053804 & \multicolumn{2}{|c|}{ Durbin-Watson statement } & 2.170884 & F-statistic \\
\hline \multicolumn{3}{|c|}{0.143986} & & Prob (F-statistic) \\
\hline
\end{tabular}

The result showed that there's a negative and significant relationship between productivity and financial growth.

\section{Results and Implication of the Estimated Results}

The result shows that there's a negative and significant relationship between the profit capitation and deposit capitation compared to administrative costs to overall costs (i.e. there's a positive and significant relationship between profitability and productivity because decreasing the administrative cost to overall costs will increase the productivity) but there isn't any significant relationship between the profit capitation and asset input rate.

The results also show that the second hypothesis is not rejected but is accepted based on the estimations.

There's a negative and significant relationship between productivity and financial growth indexes.

\section{References}

[1] Wong-On-Wing, B., Guo, L., Li, W. and Yang, D. (2007) Reducing Conflict in Balanced Scorecard Evaluations. Accounting, Organizations and Society, 32, 363-377.

[2] Banker, R., Potter, G. and Srinivasan, D. (2000) An Empirical Investigation of an Incentive Plan That Include Nonfinancial Performance Measures. The Accounting Review, 75, 65-92.

[3] Niven, P.R. (2009) Balanced Scorecard Step by Step for Government and Nonprofit Agencies. John Wiley Sons, New York, 8.

[4] Olve, G. and Sjostrand, A. (2005) The Balanced Scorecard.Translated by Soleymani, A.R., Center of Iran Industrial Research and Education Publication, Tehran, 141.

[5] Arban, A. and Buglino, L. (2010) A Multimentional Performance Model for Consolidating Balanced Scorecards. Advances in Engineering Software, 34, 339-349.

[6] Hoque, Z. and James, W. (2012) Linking Balanced Scorecard Measures to Size and Market Factors: Impact on Organizational Performance. Management Accounting Research. 